\title{
REVIEW
}

\section{Childhood accidents: epidemiology, trends, and prevention}

\author{
Alison Kemp, Jo Sibert
}

The prevention of injuries to children remains a high priority for society. Doctors who are confronted with a seriously injured child in the accident and emergency (A\&E) department or in the children's wards would like to have prevented the episode rather than be treating it. The steps needed to do this are not easy and involve actions from people far removed from the medical context. ${ }^{1}$ For instance, a pedestrian road traffic accident might have been prevented by introducing traffic calming. This involves the local community, local politicians, traffic engineers, and town planners.

It is very tempting to try to prevent all accidents. However, when this has been tried it has rarely been successful. The focus should be on individual injuries, with collection of details about the mechanism of the accident to determine the epidemiology and causes of injury. This makes it possible to formulate strategies for prevention which can then be implemented and evaluated. However, the successful implementation of these strategies can be extremely difficult.

\section{Mortality from accidents}

Accidents are the most frequent causes of death of children over one year of age. Therefore any efforts to reduce mortality in childhood must address the reduction of accidents. In 1992, 559 children under 14 years of age died in England and Wales from injuries and poisoning. ${ }^{2}$ Road traffic accidents remain the most frequent cause of accidental death in children, accounting for an average of 240 deaths each year. They are also an important cause of death in young people, in particular young men. Child pedestrians deaths are the most numerous but many die on bicycles and in cars. Deaths from conflagrations and complications of burns and scalds have been highlighted, with house fires due to foam furniture causing just under 100 deaths a year in England and Wales. Nearly 50 children die each year from drowning in England and Wales. Table 1 sets out the causes for accidental deaths for England and Wales for 1992.

\section{Morbidity from accidents}

Accidents are a significant cause of handicap in children. Head injuries, which may follow pedestrian, cycle, or passenger road traffic accidents, falls, or child abuse, are the major cause of handicap following injury. Children may also be brain damaged following near drowning or suffocation episodes. Burns, scalds, and road traffic accidents may result in scarring and cosmetic damage which can be psychologically damaging to the child. The child may be damaged by post-traumatic stress following the accident or from the effects of the subsequent hospital admission and treatment.

Childhood accidents are a frequent cause of attendance at A\&E departments. Studies in Sheffield and South Glamorgan ${ }^{3}$ have shown that in one year one in five of the child population attended hospital because of an accident. We have recently reviewed these figures and found that one child in four now attends the A\&E department in Cardiff in one year. ${ }^{4} \mathrm{On}$ the basis of such studies, it has been estimated that 2.33 million children attend an $A \& E$ department in England and Wales annually. Although the majority of these injuries are relatively trivial, among them there are many that are serious. Twelve per cent of children attending an A\&E department have fractures. Childhood accidents are also a frequent cause of admission to hospital. Between $5 \%$ and $10 \%$ of the children who attend hospital require admission.

\section{Aetiological factors in childhood accidents}

Social factors are important risk factors in childhood accidents. ${ }^{5}$ Road traffic accidents are five times more common in children whose fathers come from the social class $\mathrm{V}$ than in children from professional families. The death

Table 1 Accidental deaths from injuries and poisoning, England and Wales 1992, 0-14 years

\begin{tabular}{lrrr}
\hline Cause & \multicolumn{1}{c}{$M$} & \multicolumn{1}{c}{$F$} & Total \\
\hline Transport accidents & 185 & 96 & 281 \\
Accidental poisoning & 6 & 4 & 10 \\
Accidental falls & 29 & 8 & 37 \\
Medical misadventure & 2 & 3 & 5 \\
Fire and flames & 47 & 35 & 82 \\
Environmental & 2 & 4 & 6 \\
Accidental drowning & 34 & 13 & 47 \\
Inhalation & 9 & 8 & 17 \\
Mechanical suffocation & 35 & 6 & 41 \\
Others & 22 & 11 & 33 \\
& & & \\
Total & 371 & 188 & 559 \\
\end{tabular}


rate in boys aged $0-14$ years from fires is 15 times higher in social class $\mathrm{V}$ than in boys from professional families. Similar social class gradients are seen in other types of accidents, with disadvantaged children having more accidents. There is an increased injury rate in children of single mothers, who are often among the poorest and most isolated groups in the population. ${ }^{6}$

The reasons for this social gradient in childhood accidents are complex. Poorer families live in poor housing and in more dangerous environments. It is much easier for a child to have a road accident if his or her house opens straight onto a main road in the inner city than if he lives in a detached house with a front garden.

Psychosocial stress factors are also involved in the aetiology of many childhood accidents. Backett and Johnston ${ }^{7}$ and Sibert ${ }^{8}$ studied the social pattern of road accidents and accidental poisoning in childhood respectively and found that stress factors were more common in cases than in controls. Brown and Davidson ${ }^{9}$ found that accidents were more common in children of psychiatrically disordered mothers than in controls. Beautrais et al found adverse life events to be a factor in deaths from injury. ${ }^{10}$

The question of personality in childhood accidents, and whether children can be accident-prone, is difficult. It is likely that accident proneness is multifactorial. We know that it is related to the environment, both physical and social, and it is useful to recognise an accident-prone community. Some children have underlying disorders that are associated with poor motor coordination or poor concentration span, with little awareness of danger, for example, dyspraxia, attention deficit hyperactivity disorder. These children are often described as accident-prone.

\section{Prevention of childhood accidents}

The prevention of accidents is an important public health issue. They are unlikely to be prevented by blanket campaigns that attempt to cover all accidents, as the epidemiology and causes are so varied. Well researched multidisciplinary action on individual types of accidents may be successful. ${ }^{1}$ In preventing a particular type of accident a methodological approach is needed. This must first look at the size and nature of the problem, then decide what preventative solutions are possible. These can be implemented and evaluated on a small scale and then introduced more widely when they have proved to be effective. There are three main strategies for accident prevention: education of children and parents, changing the environment of the child, and enforcing changes in the environment by law. Research suggests that while in some fields education is important, most successes in accident prevention have followed environmental changes. Educational campaigns by themselves are only of limited value. ${ }^{11-13}$

An example of a methodological approach to the prevention of accidents is the prevention of accidental child poisoning. This is a significant problem for children under five. The epidemiology has been studied and education campaigns have been evaluated and shown to be ineffective. ${ }^{14}$ An environmental solution (child resistant containers (CRCs)) was evaluated on a small scale, ${ }^{15}$ shown to be worthwhile, and then introduced more widely, both in the United States ${ }^{1617}$ and the United Kingdom. This resulted in a reduction in the numbers of children admitted to hospital with accidental poisoning. ${ }^{1819}$

Accident prevention and injury control is the responsibility of many government departments, from the Department of Health to the Home Office. This means there is difficulty getting a focus on the problem, as any successful intervention is likely to need a multidisciplinary team approach.

ENVIRONMENTAL CHANGE IN CHILD ACCIDENT PREVENTION

Environmental change can prevent accidents. ${ }^{1}$ Examples are:

Pedestrian road traffic: Traffic calming. ${ }^{20}$

Bicycle injury: Cycle helmets ${ }^{21-25}$; attention to bicycle design. ${ }^{26}$

Passenger in cars: Seat belts and car safety seats $^{2728}$; car design. ${ }^{29}$

House fires: Smoke detectors. ${ }^{30-33}$

Nightdress fires: Reducing flammability of nightdresses. ${ }^{3435}$

Bath scalds: Thermostat reduction of the temperature of the hot water in domestic systems. $^{3637}$

Drowning in municipal pools: Supervision of swimming pools by Health and Safety regulations has meant that only one child dies per year in England and Wales. ${ }^{38}$

Drowning in water at home: Fencing domestic swimming pools prevents drowning in Australia. ${ }^{39-42}$

Falls from windows: Window guards reduced falls in "Children Can't Fly" programme in New York. ${ }^{43}$

Falls in playground: Attention to playground design: impact absorbing surfaces, ${ }^{4}$ reducing height of equipment. ${ }^{44}$

Accidental child poisoning: have reduced following the use of child resistant containers (CRCs). ${ }^{14-19}$

Accidental choking: Small part toy safety regulations. ${ }^{45}$

Glass injuries: Safety glass. ${ }^{4647}$

In many cases an environmental measure can be shown to be effective; however, voluntary uptake of such measures is generally poor. Environmental change needs to be enforced by law before it is used by the population as a whole. Seat belt wearing only increased significantly after seat belt legislation was introduced.

The story of cycle helmets illustrates the international evolution of an environmental solution to a problem. Analysis of accident and emergency admissions showed that a significant number of children sustained severe head injuries after a cycle accident. ${ }^{48}$ 
Research based evidence includes at least five case-control studies that show the effectiveness of cycle helmets in preventing head injury:

- Thompson et $a l^{21}$ in Seattle studied 235 patients with head injuries. As controls they used two groups of patients with bicycle injuries not involving the head. Seven \% of the case patients were wearing helmets, compared to $24 \%$ of emergency room controls and $23 \%$ of the second control group. Of 99 cyclists with serious head injury only $4 \%$ wore helmets. Cyclists had a $85 \%$ reduction in their risk of head injury by wearing helmets.

- Maimaris et al ${ }^{22}$ from Cambridge reviewed 1040 patients. Cycle helmets were worn by 114. Head injuries involved $4 \%$ of helmets wearers and $11 \%$ of non-wearers. This was a protective factor of 3.25 for wearing helmets.

- Thomas et al from Brisbane, Australia, ${ }^{23}$ studied 102 children with bicycle head injuries compared to 278 other injuries. They showed a reduction of bicycle head injuries of $63 \%$ as a whole and of loss of consciousness by $86 \%$ by the use of helmets.

- McDermott et $a l^{24}$ looked at the effectiveness of bicycle helmets in Victoria, Australia. In a study of 1710 casualties head injury was reduced by $45 \%$ by approved helmets.

- Spaite et $a l^{25}$ from Tuscon, Arizona, undertook a prospective analysis of injury severity among helmeted and non-helmeted bicyclists involved in collisions with motor vehicles (116 wore helmets; 168 did not). Mean injury severity score was much greater in those not wearing helmets $(P<<0.001)$.

In addition to this compelling evidence, there is also evidence of a reduction in injuries following increases in cycle helmet use: three of these studies followed the introduction of safety legislation.

- Rivara et $a l^{49}$ reviewed the Seattle bicycle helmet campaign for children. Helmet use rose from $5.5 \%$ in 1987 to $40.2 \%$ in 1992 . Bicycle head injuries fell by $66.6 \%$ over the same time period.

- Cameron et $a l^{50}$ reviewed the introduction of a bicycle helmet law in the state of Victoria, Australia. They showed that the number of insurance claims for bicycle head injuries admitted to hospital fell by $48 \%$ in the first year and $70 \%$ in the second.

- Pitt et $a l^{51}$ reviewed the effect of a bicycle helmet campaign followed by law in Queensland, Australia. They showed a decline of bicycle head injuries with increasing helmet use.

State legislation regarding cycle helmets has been introduced sporadically in Australia and the USA. Its effect continues to be monitored. No such action has been taken here in the United Kingdom. Despite the research evidence, arguments continue as to whether cycle helmets are the single solution to the problem. It is likely that the optimum way to reduce cycle injuries to children consists of a combination of designated cycle tracks, cycle proficiency education, and cycle helmet legislation.
HEALTH EDUCATION AND CHILDHOOD ACCIDENTS Several studies have shown that education campaigns to prevent accidents to children are by themselves ineffective. ${ }^{11-13}$ There is evidence, however, that health visitors visiting the home and giving specific attention to accident prevention can make a difference to the way families behave, ${ }^{5253}$ in particular with regard to the installation of safety equipment. Health education must therefore be directed on a one to one partnership basis by people such as the health visitor or the general practitioner. We need to deliver safety education to complement environmental measures in many instances. Parents need to be aware of the importance of installing car safety seats correctly. Families need to be reminded to check smoke alarms regularly and keep a battery in them. Before environmental measures are introduced by legislation, education campaigns are needed to encourage voluntary uptake so that ergonomic and effectiveness evaluation can be undertaken. Education can empower public opinion to institute environmental change. For instance, parents can be educated that safe playground equipment is needed for their children. They can then pressure the local authority to act.

\section{Research on childhood injuries}

Any programme of injury prevention in childhood should be based on clear evidence and research. There needs to be a comprehensive injury surveillance system underpinning accident prevention. Accurate collection of data is vital to prioritise areas for research and intervention, to evaluate intervention, and to monitor change. Although injuries to children play such a major role in morbidity and mortality in childhood there is no programme of research. The three academic departments of child health in the United Kingdom (Newcastle, Wales, and the Institute of Child Health in London) with a major interest in injury control have to struggle for funding. The subject falls between the Medical Research Council and the Education and Science Research Council, and relatively few projects have been funded. The subject is not a popular one with major charities. The multiplicity of government departments involved also means that funding opportunities are limited.

\section{Action on childhood accidents}

In 1977 S D M Court and R H Jackson were instrumental in the formation of the Child Accident Prevention Trust (CAPT) in England. The trust brings many disciplines together to foster research and action on accidents to children, and there are similar groups in other parts of the world.

As well as national action on accident prevention, local action is needed to introduce safety measures. In Sweden, public health physicians, led by L Svanstrom from the Karolinska Institute in Stockholm, developed the concept of local action through the Safe Communities projects. Using this approach, 
projects in Sweden reduced home accidents by as much as $20 \% .^{54}$ The First World Injury Control Conference in 1989 approved a manifesto for safe communities: "Safety-a universal concern for all". ${ }^{567}$ The Second World Conference in Atlanta confirmed this. Throughout the United Kingdom there are small groups under taking community projects. Much is done on a low budget or voluntary scale.

In the United Kingdom the main costs of childhood injuries are felt by the families and by the NHS. The main costs of prevention are undertaken by local authorities. There clearly needs to be collaboration between health authorities, NHS trusts, and local authorities if success is to be achieved. A national safety agenda for children would focus work and give direction to child accident and injury prevention at a governmental level and on local level.

\section{Summary}

Accidents are the most common cause of death in children over one year of age. Prevention remains a high priority. We have reviewed the current epidemiology of childhood accidents and their prevention, and made recommendations for the future

In 1992, 559 children died in United Kingdom as a result of an accidents -240 from road traffic accidents and 100 from burns and scalds. Every year 50 children drown. Accidents cause significant disability to children. Many children, up to one in four of the population in urban areas, attend accident and emergency departments, and $5-10 \%$ of these are admitted to hospital. Accident risk factors include low social class, psychosocial stress, an unsafe environment, and child developmental disorders. Research has shown that prevention is best achieved by making the child's environment safer, often through legislation.

Insufficient resources have been put into both research into childhood injuries and preventive work in communities. Collaboration between health authorities, NHS trusts, local authorities and community networks is vital if success is to be achieved. A national safety agenda for children would focus the attention that this problem deserves.

1 Sibert JR. Accidents to children: the doctor's role Education or environmental change? Arch Dis Child 1991;66:890-4.

2 Office of Population Censuses and Surveys. Deaths by accidents and violence. Quarterly Monitors, DH4 series, 1992.

3 Sibert JR, Maddocks GB, Brown M. Childhood accidents-an endemic of epidemic proportions. Arch Dis Child 1981;56:226-8.

4 Mott A, Evans R, Rolfe K, Potter D, Kemp KW, Sibert JR. Patterns of injuries to children on public playgrounds. Arch Dis Child 1994;71:328-30.

5 Child Accident Prevention Trust. Basic principles of child accident prevention. London: CAPT, 1989.

6 Roberts I, Pless B. Social policy as a cause of childhood accidents: the children of lone mothers. BMJ 1995;311: $925-7$.

7 Backett EM, Johnston AM. Social pattern of road accidents to childhood. Some characteristics of vulnerable families to childhood. Som

8 Sibert JR. Stress in families of children who have ingested poisons. BMJ 1975;3:87.

9 Brown GW, Davidson S. Social class, psychiatric disorder of mother and accidents to children. Lancet 1978; ; $378-81$.
10 Beautrais AL, Fergusson DM, Shannon FT. Life events and childhood mortality: a prospective study. Pediatrics 1982 70:935-9.

11 Minchom P, Sibert JR Does health education prevent childhood accidents. Postgrad Med J 1984;60:260-2.

12 Schlesinger ER, Dickson DG, Westaby J, Logrillo VM, Maiwald AA. A controlled study of health education in accident prevention: the Rockland County child injury project. Am J Dis Child 1966;111:490-6.

13 Sibert JR, Williams H. Medicine and the media. BMJ 1983; 286:1893.

14 Harris DW, Karindiker DS, Spencer MG, Leach RH, Bower AC, Mander GA. Returned medicines campaign in Birmingham 1977. Lancet 1979;ii:599.

15 Scherz RG. Prevention of childhood poisoning. Pediatr Clin North Am 1970;17:713.

16 Walton WrW. An evaluation of the Poison Prevention Act. Pediatrics 1982;69:363-70.

17 Clarke A, Walton WW. Effect of safety packaging on aspirin ingestion by children. Pediatrics 1979;63:687-93.

18 Sibert JR, Craft AW, Jackson RH. Child resistant packaging and accidental child poisoning. Lancet 1977;ii:289-90.

19 Jackson RH, Craft AW, Lawson GR, Sibert JR. Changing pattern of poisoning in children. BMJ 1985;287:1468

20 Tight MR. A study of accident involvement and exposure to risk of child pedestrians on journeys to and from school in urban areas. Crowthorne, Buckinghamshire: Transport and Road Research Laboratory, 1988.

21 Thompson R, Rivara FP, Thompson DC. A case control study on the effectiveness of bicycle safety helmets. N Engl J Med 1989;320:1361-7.

22 Maimaris C, Summers CL, Browning C, Palmer CR. Injury patterns in cyclists attending an accident and emergency department: a comparison of helmet wearers and nonwearers. BMJ 1994;308:1537-40.

23 Thomas S, Acton C, Nixon J, Battistutta D, Pitt WR, Clark $R$. Effectiveness of bicycle helmets in preventing injury in children: a case control study. BMJ 1994;308:173-6.

24 McDermott FT, Lane JC, Brazenor GA, Debney EA. The effectiveness of bicycle helmets: a study of 1710 casualties. J Trauma 1993;34:834-44.

25 Spaite DW, Murphy M, Criss EA, Valenzuela TD, Meislin HW. A prospective analysis of injury severity among helmeted and non helmeted bicyclists involved in collisions with eted and non helmeted bicyclists involved in
motor vehicles. J Trauma 1991;31:1510-6.

26 Sibert JR. Bicycle injuries in childhood. BMJ 1977;i:613-4

7 Partyka SC. Lives saved by seat belts from 1983 throug 1987. NHTSA technical report, DOT HS 807324 . Springfield, Virginia: National Technical Information Service, 1988.

28 Johnston C, Rivara FP, Soderberg R. Children in car crashes: analysis of data injury and use of restraints. Pediatrics 1994;93:960-5.

29 Lund AK, Ferguson SA. Driver fatalities in 1985-1993 cars with airbags. J Trauma 1995;38:469-75.

30 Mierley MC, Baker SP. Fatal house fires in an urban population. JAMA. 1983;249:1466-8.

31 Runyan CW, Bangdiwala SI, Linzer MA, Sacks JJ, Butts J. Risk factors for fatal residential fires. N Engl J Med 1992 327:859-63.

32 Council on Scientific Affairs. Preventing death and injury from fires with automatic sprinklers and smoke detectors. JAMA 1987;257:1618-20.

33 Chandler SE. The incidence of residential fires and the effect of housing and other social factors. BRE information paper 1 , P20/79. Watford: Building Research Establishment, 1979.

34 Eadie PA, Williams R, Dickson WA. Thirty-five years of paediatric scalds are lessons being learned? $\mathrm{Br}$ J Plastic Surg 1995;48:103-5.

35 Tempest MN. A survey of domestic burns and scalds in Wales during 1955. BMJ 1956;i:1387-92.

36 Murray JP. A study of the prevention of hot tap water burns. Burns 1988;14:185-93

37 Feldman KW, Schaller RJ, Feldman JA, Mcmillon M. Tap water scald burns in children. Pediatrics 1978;62:1-7.

38 Kemp AM, Sibert JR. Drowning and near drowning in children; lessons for prevention. BMJ 1992;304:1143-6.

39 Pearn JH, Nixon J. Are swimming pools becoming more dangerous? Med J Aust 1977;2:702-4.

40 Milliner N, Pearn J, Guard R. Will fenced pools save lives? Med J Aust 1980;2:510-11.

41 Langley J. Fencing of private swimming pools in New Zealand. Community Health Stud 1983;7:285-9.

42 Orlowski JP It's time for pediatricians to 'rally round the pool fence'. Pediatrics 1989;83:1065-6.

43 Speyel CM, Linderman F. Children Can't Fly. A program to prevent mobility and mortality from window falls. Am J Public Health 1977;68:1143-7.

44 Chalmers DJ, Marshall SW, Lagley JD, Evans MJ, Brunton CR, Kelly A, et al. Height and surfacing as risk factors in falls from playground equipment: a case-control study. Injury Prev 1996;2:98-104.

45 Nixon JW, Kemp AM, Levene S, Sibert JR. Suffocation choking and strangulation in childhood in England and Wales: epidemiology and prevention. Arch Dis Child 1995; 71:7-14.

46 Jackson RH. Lacerations from glass in childhood. BM 1981;283:1310-2.

47 Child Accident Prevention Trust. Architectural glass accidents to children. Occasional paper 3. London: CAPT, 1982.

48 Clarke AJ, Sibert JR. Why child cyclists should wear helmets. Practitioner 1986;230:513-4. 
49 Rivara FP, Thompson DC, Thompson RS. The Seattle children's bicycle helmet campaign: changes in helmet use and head injury admissions. Pediatrics 1994;93:567-9.

50 Cameron MH, Vulcan AP, Finch CF. Mandatory bicycle helmet use an evaluation. Accid Anal Prevent 1994;26:325-7.

51 Pitt RW, Thomas S, Nixon J, Clark R, Battistutta D, Acton C. Trends in head injuries amongst cyclists. BMJ 1994:308:177.

52 Colver AF, Hutchinson PJ, Judson EC. Promoting children's home safety. BMJ 1982;285:1 177-80.

53 Roberts I, Kramer M, Suisa S. Does home visiting prevent Roberts I, Kramer $M$, Suisa $S$. Does home visiting prevent
childhood injury? A systematic review of randomised conchildhood injury? A systematic revie
54 Karolinska Institutet. Research on community safety promotion. Sundyberg, Sweden: Karolinska Institutet Department of Social Medicine, 1992.

55 Schelp L. Community intervention and changes in accident pattern in a rural Swedish municipality. Health Promotion 1979;2:109-25.

56 First World Conference on Accident and Injury Prevention, Stockholm 1989: Manifesto for safe communities. Geneva: World Health Organisation, 1989.

57 Sundstrom $M$, Svanstrom L Criteria for the safe community network. Stockholm: WHO Collaborating Centre/ Karolinska Institute, 1996.

\title{
Pre-Hospital Immediate Care
}

\author{
"Towards Evidence-Based Pre-Hospital Care"
}

\section{One day conference}

\section{Thursday 5th March 1998 \\ Commonwealth Institute High Street Kensington, London W8}

Following the success of the first Pre-hospital Immediate Care conference held in March 1997, this second conference will focus on evidence-based pre-hospital care-a method ensuring that clinical decision making is based on the best available evidence.

The conference is aimed at:

- Pre-hospital care and the emergency services

- Emergency doctors and nurses

- Paramedics

- EMTs

- Anyone with a strong interest in pre-hospital care.

\section{Scientific programme}

The scientific programme will be made up of plenary sessions combined with a series of practical workshops. Keynote speakers will address areas of growing importance.

\section{Posters and free papers-call for abstracts}

For authors' instructions and further information please contact Kathryn Sims, BMJ Publishing Group, BMA House, Tavistock Square, London, WC1H 9JP, Tel 0171383 6795, Fax 0171383 6668, Email 101317.477@compuserve.com

\section{Exhibition}

A commercial exhibition will take place during the conference. Companies or organisations wishing for further information should contact Jane Lewis at the address below.

\section{Registration}

For a registration form and further information please contact Jane Lewis, BMA Conference Unit, BMA House, Tavistock Square, London, WC1H 9JP. Tel 0171383 6605, Fax 0171383 6663, Email JaneLewis@BMA.org.com 